\title{
AN ASSESSMENT ON ARTIFICIAL INTELLIGENCE PRACTISES IN THE EUROPEAN UNION
}

\section{Oğuz GÜNER*}

\section{Abstract}

Artificial Intelligence (AI) has a game-changing role in countries' economic growth and will transform both societies and the way in which people live and work in near future. AI will let machines to present human-like cognition, it will seize jobs, drive the vehicles, decide on behalf of people and many more. However, impact of AI technology in the future cannot be exactly predicted.

This uncertainty brings both potential and risks together for governments and states. States are supposed to have several roles to play in global AI competition. Defining a national AI strategy, setting an agenda with stakeholders, strengthening research and development infrastructure, allocating budget and funds and designing curriculum for education and trainings of the citizens are some of the policies and projects of the governments.

The European Union (EU), with the intention of becoming world-leading region for AI, has designed numerous policy sets and strategies and allocated certain amount of funds for the cultivation of AI projects.

Keywords: European Union, Artificial Intelligence, Digitalisation, Artificial Intelligence for Europe.

\section{AVRUPA BİRLİĞİ'NDE YAPAY ZEKÂ ÇALIŞMALARINA DAİR BİR DEĞERLENDİRME}

$\ddot{O}_{z}$

Yapay Zekâ (YZ), ülkelerin ekonomik büyümesinde önemli bir role sahip olup, yakın gelecekte hem toplumları hem de insanların yaşam tarzlarını önemli dönüşümlere uğratacaktır. YZ teknolojileri tıpkl insanlar gibi bilişsel yeteneklere sahip olacak, insanların mesleklerini elinden alacak, araçları

* Dr., Visiting Fellow, Université de Strasbourg, Sociétés, Acteurs, Gouvernement en Europe, e-Mail: oguzguner@gmail.com, orcid.org/0000-0003-1619-579X 
kullanacak ve insanlar adına karar alabilecektir. Ancak YZ teknolojilerinin gelecekte nasıl bir etki göstereceği tam olarak öngörülememektedir.

$\mathrm{Bu}$ bilinmezlik hükümetlere ve devletlere hem potansiyel hem de risk sunmaktadır. Devletler, küresel YZ yarışında yer alabilmek için çeşitli görevler üstlenme gerekliliği hissetmektedir. Ulusal YZ stratejisinin belirlenmesi, çok paydaşlı programın hazırlanması, araştırma ve geliştirme altyapısının güçlendirilmesi, bütçe ve fonların tahsis edilmesi ve vatandaşların eğitimi için ilgili müfredat değişikliğinin yapılması gibi hükümetlerden beklenen politika ve projeler bulunmaktadır.

Dünyanın önde gelen YZ bölgelerinden biri olmayı amaçlayan Avrupa Birliği (AB) de bu hususta çeşitli politika setleri tasarlamış, stratejiler hazırlamış ve $Y Z$ projelerinin gerçekleştirilmesi için fon ayırmıştır.

$B u$ çalışma AB'nin YZ politikalarını, AB kurumlarının programları ve üye ülkelerin stratejileri çerçevesinde ele almaktadır. Çalışmada öncelikle YZ tanımlanmış, sonrasında stratejisini duyurmuş olan AB üye devletlerinin ulusal $Y Z$ stratejileri ve $A B$ 'nin politikaları incelenmiştir. Çalışmada AB'nin Çin ve $A B D$ gibi küresel aktörler karşısında zaylflayan rekabet edebilirlik gücünü artırabilmesi için daha etkin politikalar uygulaması, ekosistemini ve nitelikli iş gücünü güçlendirmesi gerektiği sonucuna ulaşılmıştır.

Anahtar Kelimeler: Avrupa Birliği, Yapay Zekâ, Dijitalleşme, Avrupa için Yapay Zekâ.

\section{Introduction}

While the tools of prosperity were large wetlands, animal herds and stables in the Middle Age, trade caravans and ships in Modern Age, factories and industrial production in the $20^{\text {th }}$ Century, tools of prosperity are knowledge and knowledge management today.

Since the Industrial Revolution in 1760s, machine power has been replacing human muscle power and this replacement process has kept going expeditiously. Technology-driven projects such as invention of printing techniques, radio, television, computer and rise of information age have contributed to information processing without constraints of time and space. Especially the invention of computers and World Wide Web (WWW) has brought tremendous growth in informatics, data processing, digitalisation and automation.

The invention of WWW and computers is breakthrough for AI which has been replacing human intelligence with machines. Marriam Webster Dictionary defines AI as "the capability of a machine to imitate intelligent human behaviour". This definition is limited since AI can be defined as "the study of 
making computers do things that human needs intelligence to do", so it basically covers mimicking or simulating human thought processes and making computer achieve the tasks assigned (Munakata, 2008: 2).

Even though the first theory of computation and future of machine intelligence was developed by Alan Turing, the phrase of AI was first used by computer scientist John McCarthy in 1955. AI is simulating human intelligence on a machine to identify and solve a problem via using right piece of knowledge in its memory. The machine must have learning capability in order to possess perception, thinking and acting rationally, thus the machine can be intelligent (Konar, 2000: 26-27).

AI can be characterized as advanced version of computing systems and variations of its techniques have expanded since 1980s and started to be used in commercial and industrial settings since 1990s (Munakata, 2008: 2).

Knowledge and reasoning of smart devices are important for humans. Because humans have limitations in terms of attention span, analyse and memory. Additionally, humans are subjective, slower and forgetful (Tecuci, 2012: 178). These features bring competitive advantages to smart devices and reveal the importance of AI. AI techniques such as knowledge-based reasoning, machine learning, natural language processing or environment perception are ever-increasingly being employed by today's technologies. Devices equipped by AI technologies are able to make smart decisions after they perceive the information they need from their environment (Arsenio, 2015: 73).

It is well-known fact that AI technologies will transform work, however there is not going to be a mass job disappearance in short term. According to the study of the McKinsey Institute, almost $10 \%$ of all work tasks are those in which over $90 \%$ of the work involved in the task can be automated by 2030 . Also, it is estimated that the proportion of autonomous vehicles on the roads could reach to $25 \%$ by 2030 . (Balasubramanian, Libarikian, and McElhaney, 2018). According to a study conducted by Groupe Speciale Mobile Association (GSMA), number of the connected device will reach 25 billion worldwide by 2025. These connections among the devices are executed by Internet of Things (IoT) technology (cellular or non-cellular) which allows devices to communicate, analyse the data shared and to use the intelligence inserted to core of the devices. Proliferation of IoT devices requires more pervasive intelligence and connectivity, thus $\mathrm{AI}$ has been increasingly integrated into connected devices, services and networks (GSMA, 2018: 3-5). AI technology has been used in many industries and become prevalent with various services such as self-driving cars, intelligent robots, smart healthcare technologies and chat boats in companies' customer services units. These services are driven autonomously and are seen as a key to the future of the business. 
With regard to AI strategy, the role of the governments and states is to define policy sets to draw its road in AI. Certain countries such as the United States (USA), China, Canada and Japan declared their AI strategies and defined their priorities in AI sector.

The EU has attached importance to AI activities from the beginning and aimed to keep itself at the forefront of technological competitiveness. In this context, the EU defined various policy sets and allocated funds for AI activities and projects. Additionally, certain European countries declared their AI policies and strategies. As a supra-national institution, the EU's AI-related policies are mostly composed of projects, funds, various institutions' activities and instruments such as European Innovation Council, European Research Council, research programs and framework programs, and they propose to develop the AI activities under its policy instruments in science, research and innovation.

The study puts an assessment on the position of the EU compared to other global actors such as China and the USA. However, the study covers AI strategies of the EU and states of the member countries as well.

The study is categorized in four sections. Initial part displays the AI industry and leading actors in the sector. The second part describes the EU's attempts in $\mathrm{AI}$ and compares the EU in terms of private sector, patent production and scientific effectiveness. The third part defines contents of declared AI strategies of the EU states and the final part condenses and concludes the study.

As the policy or policy evaluation in AI is a brand-new subject, there is almost no prior research worth being employed in this study. Prior research and studies in AI are mostly discussed within the context of machine learning, software development, coding or computational sciences. In this regard, the author has limitations on the basis of literature review and has difficulty to lay a theorical foundation. Thus, the study is limited to actual reports and living strategy documents. However, discussing AI policies and strategies, particularly in the EU perspective, makes the study authentic.

\section{AI Industry and Leading Powers}

AI is used in various fields such as marketing, advertising, access management and cyber-security and AI market is thought to be around \$21 billion in 2018 and estimated to reach $\$ 190$ billion by 2025 thanks to growing big data, cloud-based applications and virtual assistants (Research and Markets , 2018). Most of the information and news regarding the developments in AI industry is obtained from companies and suppliers of AI technologies. Therefore, private companies are the main drivers of AI technologies. Although few products are on the market at present, it seems accurate that AI will open a new frontier for future struggles. Investment on AI is growing rapidly, which 
will possibly cause the most significant technology battle in world history which is dominated by large companies (McKinsey Global Institute, 2017a).

Today, AI is one of the most widely-esteemed topics of economic world. Google CEO Sundar Pichai believes that AI is more important than the invention of fire and electricity (CNBC, 2019). However, distribution and adoption of AI technology hasn't been spread throughout the world equally. Depending on countries' infrastructure, policies, and regulatory framework, high adoption of AI technology is substantially shared between two geographies: North America and China. Grand technology actors such as Amazon (USA), Google (USA), Apple (USA), Facebook (USA), Microsoft (USA), Baidu (China), Alibaba (China) and Tencent (China) (collectively known as BAT) dominate the AI industry (GSMA, 2018: 3-5) and interestingly none of these companies are European. Besides, most of the companies which have leaped forward in information society are either American or Asian.

The USA Government had already set an AI strategy and invested more than $\$ 1$ billion in AI-related research activities in 2016. China, with its "Next Generation Artificial Intelligence Development Plan", targets to take over global leadership by 2030 and invests in AI in massive amounts. Japan and Canada have also adopted AI strategies and have been investing in large companies in AI sector (European Commission, 2018a). However, defacto leaders of AI industry today are the USA and China. Investments of China and the USA, which also hold the largest research and development (R\&D) expenditures in the world, in AI are impressively huge. Thus, it seems that the trade war between China and the USA will escalate in near future when China's $\$ 1$ trillion of investment plan in AI by 2030 and investment with an amount of $\$ 4.5$ billion on 200 AI companies between 2012 and 2017 are taken into consideration. In order to facilitate AI innovation, China is building a huge techno-park with $\$ 2.1$ billion investment, and administration of Tianjin, a city in northern China, allocates $\$ 5$ billion for supporting AI development. A Chinese company Alibaba invested \$600 million in SenseTime which functions as AI fostered face-recognition start-up (CNBC, 2018). Even the amount of such a single investment in a company indicates magnitude of China's endeavours in AI. However, the USA is definitely the leading power of AI in terms of expenditures, R\&D and deployment at present. The Executive Order on Maintaining American Leadership in AI signed by President Trump in February, 2019 aims to strengthen the leadership position of the USA in AI, promote technology and innovation, prepare today's people and jobs for future's requirements and protect the USA's technologic leadership from acquisition by competitors and adversaries. The Order projects to foster confidence and trust of public and protect civil liberties and American values and also aims to promote sustainable investments in AI R\&D via cooperating 
with industry, international stakeholders and academia (White House, 2019). Trump's initiative directs the government institutions to invest more in AI R\&D, open data pools and share data with researchers, define technical standards and boost workforce development. If these plans and programs are stuck by, these developments are estimated to contribute to GDP by $14 \%$ by 2030. The White House believes that the private sector must lead the transformation process as the role of federal government is restricted (Bloomberg, 2019). Leading role of the private sector in AI cannot be denied. Most of the biggest AI companies such as AI Brain, Amazon, Anki, Apple, Banjo, Cloudminds, Deepmind, Facebook, Google, Intel, Microsoft, Nvidia, Twitter and SoundHound are deployed in the USA and these companies dominate the AI industry in the world.

In academic and scientific dimension, no other universities and research centres in any countries allocate as much time and budget as the universities and research centres spend in the USA. One of the most distinguished universities, Massachusetts Institute of Technology announced to invest $\$ 1$ billion -one of the largest commitments in AI ever- for establishment of a new college to train the next generation of AI and machine learning (MIT, 2019). Even this commitment indicates the gravity of the USA's approach to AI sector.

Being among the leading countries at present and aiming to be a world leader in AI by 2030, China has started to implement certain national policies sets, funds, incentives and data investments in AI sector. Being the largest data market in the world and having technology-friendly policies, China aims to be critical hub in AI technologies.

China published its first textbook on AI entitled "Fundamentals of Artificial Intelligence" to be instructed to high school students and called for AI courses in primary and secondary school curriculum (South China Morning Post, 2019). This action reveals China's ambition and long-term plans to seize the leadership in $\mathrm{AI}$ in future.

According to a report prepared by the McKinsey Global Institute, thanks to its vast population, diversified industrial infrastructure, large market and R\&D investments by big technology companies, China will possibly take over the leadership flag in AI in the world in next 10 years. In order to fulfil its farreaching potential, China formed 5 priority areas in its AI strategy: building a substantial data ecosystem, promoting traditional industries to adopt AI, setting up a legal and ethical consensus in accordance with global community, strengthening the interaction among AI talents and providing an education system which can resist against the challenges (Barton, Woetzel, Seong and Tian, 2017). 
According to some experts, China is thought to be not as sensitive as the European countries in terms of use of personal data and data protection. Additionally, compared to large companies based on Europe or the USA, Chinese companies are more advantageous because it is alleged that BAT (Baidu-Alibaba-Tencent) companies receive strong support from Chinese government (Fortune, 2019) and these companies can easily access to data pool controlled by the government, which makes them get stronger progressively.

In China, both the central government and local governments have prepared policies regarding AI development, but China's AI policy mainly focus on promoting technological developments and not comprehensively covering ethical values and security concerns. Notwithstanding, considering the AI patents and paper production in the world, China is behind the USA but ahead of the most of the developed countries such as Japan, the United Kingdom (UK), Germany and France (China Institute for Science and Technology Policy, 2018).

\section{AI Companies}

As the private sector is the key actor in AI industry, companies and start-ups thereby play a central role in various activities. Value of the USA stock market is around $\$ 34$ trillion, a quarter of which is composed of technology companies. Besides, top five companies (Apple, Amazon, Google, Alphabet, Microsoft and Facebook, the biggest investors in $\mathrm{AI}$ ) account for around $\$ 4$ trillion, which is around 33\% of total value of European market (Joint Research Centre, 2018). Not only the technology companies but also individual AI companies exist in AI industry in the world. The Figure 1 indicates that the USA hosts around 2905 companies and multiplies the number of the companies in China by four. China ranks the second in the figure, housing more companies than other countries such as the UK, India and Canada. The UK, India, Canada and Israel come after. The number of AI companies in China is more than the number of the companies in the UK, Germany and France in total. 
Figure 1: Global Distribution of Artificial Intelligence Companies

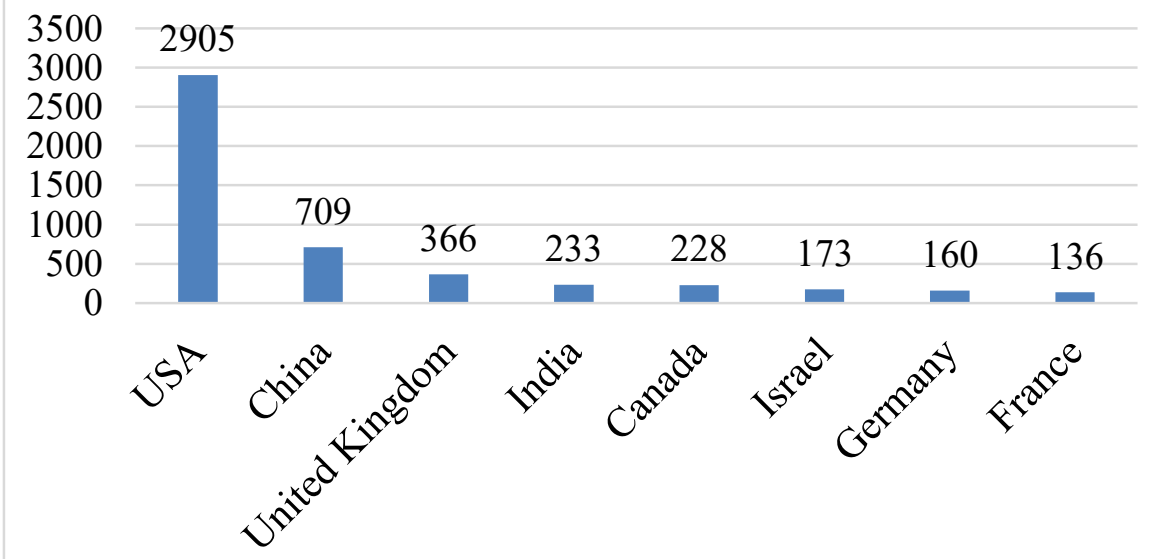

Source: Wuzhen Institute (2017).

These companies are great opportunities to direct and shape future of the industry and boost economy. Thanks to the R\&D investments of AI companies, various industries from defense and health to transportation and education are fed and supported.

\section{Patent Data and Academic Activities in AI}

From autonomous cars to online advertisements and independent medical diagnosis, AI is in everywhere and the number of new inventions and patents in $\mathrm{AI}$ is rising rapidly. One of the most important indicators in AI competition is patent data as AI is rapidly growing in patent area.

According to the "Technology Trends 2019" report prepared by World Intellectual Property Organisation (WIPO), nearly 340,000 AI patents have been filled and more than 1.6 million scientific research have been published since 1950s when the notion of AI emerged for the first time. Surprisingly, half of the inventions of AI related patents have been published since 2013. Also, machine learning patent applications increased from 9,567 in 2013 to 20,195 in 2016 with $28 \%$ annual rate of rise. Companies, especially American, Japan and Chinese ones represent the substantial parts of AI patents filings. American company IBM possesses the largest portfolio with 8,290 patent application in AI, Microsoft, another American company, takes the $2^{\text {nd }}$ place with 5,930 AIrelated patent applications. Moreover, more than two-thirds of companies which have acquired AI-related patents since 1998 are based on the USA. However, the geography of dominance differs in terms of academic and scientific studies in AI. According the report aforementioned, out of top 20 
companies filing patent application on AI, 12 are Japanese, 3 are American and 2 are Chinese. Chinese higher education institutions and research centres present 17 of the top 20 academic players in AI and out of 20 organizations producing AI-related scientific publications, 10 organizations are based on China, 6 organizations are based on USA, 2 organizations are based on Singapore and one organization is based on Japan. The USA, China and Japan account for $78 \%$ of AI-related patent filings in the world. The EU is represented by only one organization, Centre National de la Recherche Scientifique (CRNS) in France, in top 20 research organizations producing AI-related scientific publications (World Intellectual Property Organization, 2019: 13-62).

The figure below (Figure 2) displays AI-related paper creation in countries. China ranks the first and the USA ranks the second. Only five EU countries could have taken place in the top ten countries publishing AI-related papers: the UK, Germany, France, Italy and Spain. The fact remains that the number of total academic papers published by these five EU countries barely outrun the number of academic papers published by China. When the UK is excluded in the calculation due to the Brexit process, the number of AI-related papers published by all the EU countries in the top 20 hardly outruns the performance of China. Additionally, the number of papers published by the USA is almost equal to the number of papers published by Germany, France, Italy, Spain, Poland and the Netherlands in total.

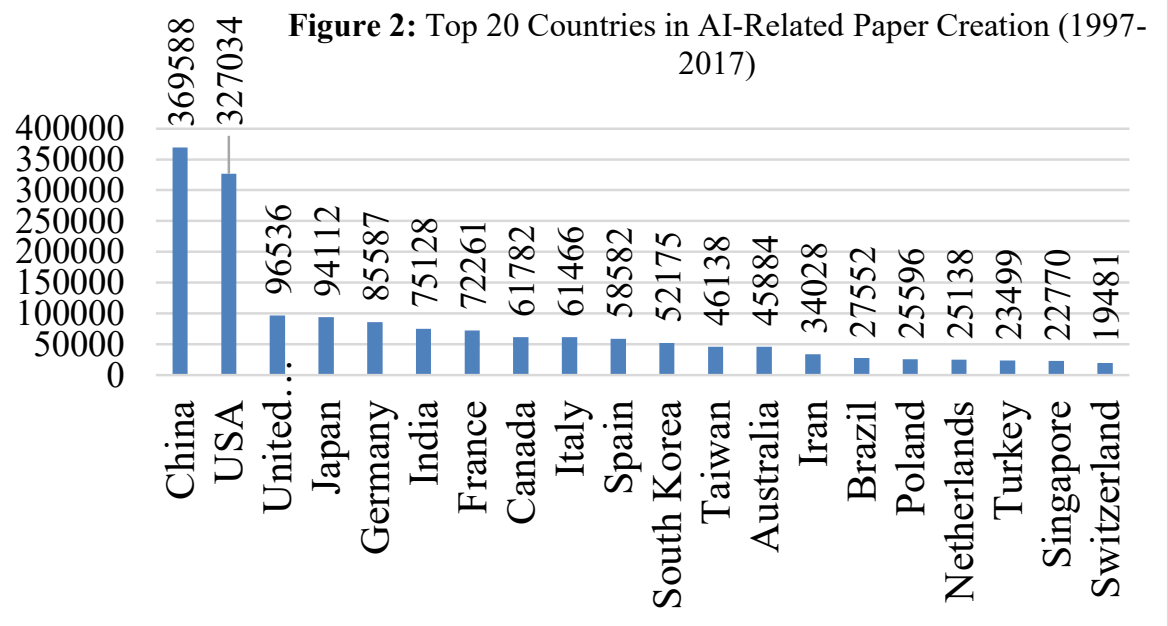

Source: China AI Development Report (2018). 
China ranks the first in not only the total number of publications but also the number of publications receiving at least one citation. According to "The National Artificial Intelligence Research and Development Strategic Plan" prepared by the US National Science and Technology Council, when the number of journal articles cited at least once, mentioning "deep learning" or "deep neutral network" is considered, China ranks the first with the score of 82, the USA ranks the second with the score of 72 and Austria ranks the third with the score of 19 in the world (National Science and Technology Council, 2016).

The graphic above does not only refer academic publications developed by countries in the field of AI. When it is accepted that AI is highly related to science and technological priorities, it should be known and accepted that this policy area is directly related to the economic situation, scientific priority and technological investments. In this context, the AI industry and capability of the countries in AI production are not only related to countries' policy priorities and cannot be explained with a single reason.

It is a crystal-clear fact that the EU has lagged behind the USA and China in terms of AI activities both for AI-related production and scientific developments. The basic reason of the EU for not being able to lead the AI production in the world can be constitutively inferred in its low performance in innovation production which is parallelly explained in total factor productivity. In the EU, lower research and development investments, lower innovation ratio and human capital, lower entrepreneurship capacity and venture capital, low ability of adopting ICT and weak economic performance are all the basic components of total factor productivity. Particularly, the European firms' weak ability to adopt ICT and weak performances of manufacturing and service sectors in preparing their organisations to new challenges of global competition can be considered as the reasons of the EU's lagging behind (Günar, 2017: 244264). In this context, the capability of the EU countries in the AI industry are dependent on those countries' innovation and ICT ecosystems. Therefore, not only the EU's overall performance, policies, strategies and investments, but also member countries' individual performances are taken into consideration.

\section{The European Union's AI Attempts}

Many EU countries have developed strategies to guide the development in AI industry. Most of these strategies concentrate on similar attentions such as strengthening research bases, establishing national AI centres, supporting the industry and SMEs, developing the share and availability of data between stakeholders and prioritizing certain sectors. The EU, in this regard, embarks to coordinate the missions and practices of member countries and aims to carry itself to a leading role in AI in the world (Joint Research Centre, 2018). 
Not only for boosting the EU's technological and industrial capability in AI but also for modernizing the education and training systems and dealing with the challenges in the labour market, the EU works with member states to have a coordinated, cooperative and collective readiness in AI competition (Joint Research Centre, 2018). Since the AI will be one of the main drivers of economic development, the EU intends to develop its industrial, technological and financial capacity via taking a forefront position at AI competition. Thus, the EU will be able to address socio-economic, legal and ethical impacts of AI over European citizens and European economy. The initial step of the EU is to increase its investment in AI by $70 \%$ and allocate up to $€ 1.5$ billion within Horizon 2020 framework program. Thus, the EU envisages connecting research centres working on AI all around the Europe, providing AI resources for users and supporting AI applications and software in key sectors (European Commission, 2019). However, current conditions show that overall Europe lags behind Asia and North America. Investments in automation technologies especially in AI are dominated by big tech companies such as Amazon, Baidu and Google which are mainly based on Asia or North America. European based companies including ABB, Bosch, BMW and Siemens invest in AI, but all the Europe is behind in external AI investments, totalled $\$ 3$ to $\$ 4$ billion in 2016, when it is compared to $\$ 8$ to $\$ 12$ billion in Asia and $\$ 15$ to $\$ 23$ billion in North America (McKinsey Global Institute, 2017b).

\section{Artificial Intelligence for Europe}

AI for Europe is a communication among the EU institutions paving the path to a Coordinated Plan on AI. The EU has a strong infrastructure with world-class researchers, research centres and start-ups and aims to be front runner especially in the sectors such as transportation, healthcare and manufacturing. To be able to feed AI systems, availability of data must be strengthened. Thus, The Commission will make data sharing easier and open more data used as raw material for AI, collecting from industries, public and scientific researches. In the Communication Document, the EU underlines the European values such as "The General Data Protection Regulation" and ensures trust and ethics which are essential for people and companies in the long term. The Communication sets out a European initiative to boost technological and industrial capacity, prepare ethical and legal framework and get ready against socio-economic changes such as education and training systems, labour markets and social protections (European Commission, 2018b).

The EU possesses strong scientific and industrial infrastructure and comprehensive legal framework in order to promote innovation. It has been funding technological projects which helped to develop various AI-supported robots such as unmanned vehicles used for agricultural purposes removing the weeds and reducing the need for pesticides, a highway pilot project to reduce 
road fatalities, a robot carrying amputees or taking care of repetitive tasks for workers since 2004. Between 2014-17, €1.1 billion was invested in AI-related research and technology projects under Horizon 2020 framework program. The EU pulls its weight, if the member states and private sector make the similar investments, total investment is expected to grow $€ 7$ billion per year, which will be more than $€ 20$ billion until the end of 2020. The Commission, on the other hand, aims to reach around $€ 500$ million between 2018-20 working with the European Investment Bank Group. In this manner, the European Commission and the European Investment Fund have allocated $€ 2.1$ billion for PanEuropean Venture Capital Funds-of-Funds Programme in order to support innovative start-ups and companies in the EU. Additionally, thanks to the European Innovation Council's budget ( $€ 2.7$ billion) between 2018 and 2020, the funded projects will be helpful for development of AI. Research projects of European Research Council and the grants and scholarships of Marie Skłodowska-Curie will contribute to AI activities. Besides, research centres in AI across Europe will be established and AI-focused research will be supported via collaboration and networking. These research centres will create innovation hubs aiming to bring businesses and users in AI and set up infrastructures to test and experiment AI products and services (European Commission, 2018b). The EU works as a backbone to improve the AI capacity of European countries and bring the European technology and industry to a leading position in international arena. In this regard, the EU instrumentalizes its funding opportunities for AI related projects and aims to develop cooperation among member countries. The Table 1 below indicates the distribution of EU-funded AI projects by country. The EU countries with special attention to AI are aligned according to their concentration.

Table 1: Distribution of EU-Funded AI Projects (2009-2018)

\begin{tabular}{|l|c|l|c|}
\hline Germany & $17 \%$ & Sweden & $4 \%$ \\
\hline United Kingdom & $13 \%$ & Belgium & $4 \%$ \\
\hline Italy & $12 \%$ & Greece & $4 \%$ \\
\hline Spain & $12 \%$ & Austria & $3 \%$ \\
\hline France & $9 \%$ & Finland & $2 \%$ \\
\hline Netherlands & $7 \%$ & Portugal & $2 \%$ \\
\hline Rest of World & $11 \%$ & \multicolumn{2}{|l}{} \\
\cline { 1 - 3 } & &
\end{tabular}

Source: Joint Research Centre (2018).

As shown above, Germany ranks the first country participating in more EUfunded AI projects than others. It is followed by the UK. Italy and Spain rank the $3^{\text {rd }}$ in the list with the same percentage rate. France ranks as the $5^{\text {th }}$ with $9 \%$, and $89 \%$ of the projects are implemented by 12 EU countries while the rest of the countries constitute $11 \%$ of the AI projects' implementation. 
The EU has certain plans and investments beyond 2020, as well. Under the multiannual framework program (2021-27), the EU aims to upgrade network of AI excellence centres, support centres for data sharing, establish more advanced testing and experimentation facilities in transportation, healthcare, agricultural food, manufacturing and supporting adoption of AI products and services in all sectors. The Commission is determined to improve the adoption of digitalisation in these sectors and wants to raise public interest and make its citizens acquire the skills and knowledge they need as the jobs started to change, transform or disappear because of the digitalisation and automation process (European Commission, 2018b).

The EU is aware of the fact that more data must be made available for the development of AI products and services across Europe. Data-rich environments provide machines and automation systems with opportunities to learn and interact with its environments and produce more data. The EU has taken important steps and opened information in public sector and researches for re-use and developed accessibility and usability of data in last 15 years. The EU's public policy encouraged the wider availability of data held by private sector. The European Commission calls private companies to recognise the importance of non-personal data use for AI-related purposes and sets a framework to develop draft AI ethics guidelines regarding the fundamental rights (European Commission, 2018b).

Digital data is a key driver of the EU's economic growth, competitiveness, innovation and job creation. The EU's data economy value was more than $€ 285$ billion in 2015, which represents over 1.94\% of the EU's GDP. Data economy of Europe is expected to increase to $€ 739$ billion by 2020 , which represents $4 \%$ of the overall EU GDP. In order to boost the data economy, more data should be available for re-use, and that is why the European Commission declared "Communication towards a common European data space". The Commission has implemented key measures for data-intensive industries. Initially, General Data Protection Regulation was applied for digital trust and Communication of "Building a European Data Economy" was launched with stakeholder and public online consultation in 2017. The EU aimed to pave a way toward a common data space in the EU. The common data space and related data-driven innovation is considered as raw material of the Digital Single Market which aspires to create new opportunities for economic growth. Use of data is rapidly widening across the EU. While the number of data companies in the EU was 254,850 in 2016 , it is expected to rise 360,000 by 2020 . The EU presents certain measures making access to data from different sources easier and re-use of data coming from different sources and sectors. With the Communication and measures proposed, the EU works towards a rapid adoption of the 
legislative procedures and aims to benefit from the data economy's opportunities (European Commission, 2018b).

\section{Coordinated Plan on Artificial Intelligence}

The European Commission's "Coordinated Plan for Artificial Intelligence" was designed to ensure the communication and organization between member states and the EU in AI and provide strategic framework for member states' AI strategies. The plan encourages member states to set their AI strategies until mid-2019. The role of the European Commission in the plan is to evaluate the strategies of member states ${ }^{1}$ if they address the real challenges or not. Thus, the Commission is going to guide the participant countries regarding "Product Liability Directive" within technological developments, and no legal regulation or law will be developed, which means the plan is not legally binding. The EU, hereby, approaches AI with its own identity, which settles on the axis of European values such as climate change, cybersecurity and ethics. The EU would like to perceive the AI in more human-centric way than any other actors. That is why "made in Europe" concern was raised in the plan (European Commission, 2018c).

The biggest contribution of the EU to AI will be "Common European Data Space". As vast amount of data is needed for machine learning, a technique of $\mathrm{AI}$, creation of data pool which is open for operations of businesses in the EU will contribute to capability of Europe. The space will collect and constitute data that participant countries will be able to access, exchange and re-use. The first use of this application will be available in 2020 under Horizon 2020 framework program. With the support of the Commission, a database of health images of patients in Europe will be created and data of volunteer patients will be gathered anonymously in the common data pool. The pool will be open to all participant countries and also, improving diagnosis and treatments via AI techniques for common forms of illnesses such as cancer is aimed via processing the data in the pool. The EU aims to develop such projects thanks to Coordinated Plan and will support start-ups and companies which need sufficient funding for their projects. A budget of $€ 100$ million is planned to be invested, $€ 45$ million of which will be allocated from Horizon 2020, and remainder will be provided from investors in Europe with the help of Fund for Strategic Investments and European Investment Fund. Also, European Innovation Council, which will fully be operated within Horizon Europe framework program between 2021 and 2027, has started to be implemented as a pilot innovation programme. $€ 2.7$ billion funding was allocated from H2020 between 2018 and 2020 to upgrade European innovation ecosystem which will

\footnotetext{
${ }^{1}$ Non-EU countries Norway and Switzerland have also participated in the coordinated plan because of their relevance.
} 
be helpful for the development of AI projects as well. Last but not least, the Commission set up "Experts Group on the Digitalisation and Future of Work" which is going to start defining strategies for employment disruption in the spring of 2019 and projects to provide $€ 700$ million to be used for advanced skills such as AI, supercomputers and cyber-security under Digital Europe Program (European Commission, 2018c). The Steering Committee will be a leading council of European AI Alliance. The Committee will work with other initiatives and stakeholders to address AI-related challenges and opportunities, develop policies and legislations, guide strategic research and strengthen Europe's competitiveness in AI (Digital Single Market, 2019).

\section{White Paper on Artificial Intelligence}

The European Commission published a White Paper on Artificial Intelligence in February, 2020. The Commission aims to preserve the EU's technological leadership and ensure new technologies for the service of all Europeans. In the White Paper, it is stressed that a European approach with human and ethical implications will be presented to AI. The EU has a strong position in terms of research funding as it pools actions, avoid duplications and leverages public and private investments in the member states. Between 2017 and 2020, funding for AI research and innovation rose to $€ 1.5$ billion which means $70 \%$ increase compared to the previous period. Additionally, there is an objective of attracting over $€ 20$ billion of total investment per year in the next decade. For the stimulation of private and investments, the EU aims to make resources of Digital Europe Programme, Horizon 2020 and European Structural and Investment Funds available. The Digital Europe Programme will be instrumentalised for strengthening the collaboration between SMEs. SMEs and start-ups will be provided a fund of $€ 100$ million to adapt their processes in AI and blockchain and more than $€ 4$ billion under the Digital Europe Programme will be proposed for AI, quantum computing, data and cloud infrastructure (European Commission, 2020).

$\mathrm{AI}$ is considered as a strategic technology offering various benefits for companies, citizens and society and the EU pays regards to human-centric, ethical and fundamental values of AI technologies. The White Paper also envisages capacity development for testing and certification of AI-enabled products and services and leave responsibilities under existing EU law and relevant authorities in certain sectors (finance, aviation, consumer protection etc.) (European Commission, 2020).

\section{National AI Strategies in European Union Countries}

The EU has no centralized, uniform AI strategy covering all the countries whereas EU countries such as Finland, Denmark, Italy, France, Sweden and Germany have individually defined numerous strategies and programs as to the 
future use of AI. However, EU member states signed a declaration of cooperation on AI to deal with the challenges collectively in April, 2018 (Digital Single Market, 2018). Besides, The Digital Single Market has adopted certain regulations to develop AI infrastructure of the EU.

Various national governments have officially started to prepare their national AI strategies since 2017, albeit focusing on different aspects of AI and defining different priorities in AI industry. Some countries launching AI strategies in the world are Canada, Japan, China, Singapore and United Arab Emirates with the aim of extending the use of AI, and most of strategies set by these countries are composed of incentive policies on scientific research, digital infrastructure, funding, skills education, standards and regulations. On the other side, some EU countries have set their AI strategies. Principal EU states setting AI strategy at national level are Finland, Denmark, Italy, France, the UK, Sweden and Germany, some of which had already stepped into action before the European Commission did.

One of the important points to be mentioned here is that the EU is not a single country, its ability to act in decision making and policy making is limited due to the lack of a single official language, central legal norms and a constitution. For this reason, the EU is not very strong in AI competition compared to countries such as the USA, China and Japan. The main factor that strengthens the EU's hand in this context and makes the EU partly competitive is the EU countries' individual AI activities and projects.

\section{Finland: Age of AI}

Finland, having already foremost enterprises and companies adopting digitalisation and new technologies, is the first country to set an AI strategy in the EU. In order to make Finland a leader in AI, Minister of Economic Affairs appointed a steering committee for the preparation of AI program. The steering committee pioneered by the former Nokia president Pekka Ala-Pietilä designed an artificial intelligence program covering "healthcare, welfare, transportation, energy and manufacturing services" in 2017. The initial report which was prepared as a map of the program highlights 8 key actions such as; "enhancement of business competitiveness, effective use of data, quick and easy adoption of AI, ensuring speciality, investments, building best public services, new collaboration models and making Finland a pioneer in AI" (Ministry of Economic Affairs and Employment, 2017).

The program report states that AI-based growth potential of Finland is very high and it can empower its competitiveness, boost its economy, produce effective and high-quality public services and provide well-being for the citizens via achieving the requirements and benefits of AI with comprehensive and intense scientific support. Basic requirement is the cooperation with 
research centres and higher education institutions. If the agile structural policies are implemented, the growth of economic value in the country is estimated to boost as double. The report in which detailed analysis of AI ecosystem is elaborated in Finland, it is stated that Finland aims to empower its AI ecosystem particularly driven by enterprises. One of the initiatives stated in the report is the establishment of Finnish Centre for AI with joint partnership of Aalto and Helsinki Universities and industries. Also, the second report entitled as "Work in the Age of Artificial Intelligence" recommends 28 policy-sets about the future of work (Ministry of Economic Affairs and Employment, 2017). The final report was released in April 2018. The report stresses innovation and integrates AI technologies in organization of work, recommends to combine technological and interaction skills and integrate into education. Additionally, the report reveals that Finland lacks of experts and education level and skills of the workers mismatch with AI requirements. Thus, mobility of labour can be a solution and move of workers to tasks that are better matching with their skills should be supported. Lastly, against any abuse of any monopolies, the government must be ready to intervene with its smart regulations (Ministry of Economic Affairs and Employment, 2018).

Finland published its final report on AI in 2019. Main aim of Finland in this AI strategy is to enhance its competitiveness in trade and industry with digital opportunities. Named as "Leading the way into the age of artificial intelligence", the report aimed to provide pathway to create new economic growth and promote wellbeing, access to efficient and cheap computing capacity, and acceleration of AI development in Finland. The background of the AI program is constructed on the idea of safeguarding economic growth, competitiveness of business, producing good public services, well-functioning society and wellbeing to the citizens. In this regard, AI is considered one of the most significant technologies which will be able to revolutionise transportation, industry, healthcare and business life. The report stresses the weaknesses of Finland and underlines the challenges such as lack of funding of public institutions compared to private companies. To utilise data in each sector effectively, information policy report was prepared and final outcome titled "Ethical information policy in the age of artificial intelligence" was submitted to Parliament in 2018. The report encourages private companies to define their own goals via self-assessment tools, share their experiences between companies and expand their strategic cooperation and joint-investment capacities. The strategy aims to make Finland a forerunner in AI and recommends to introduce the digital economy based on AI and data. With regard to future prospects, Finland prioritizes AI means for the business and invest for capacity building in digital technology, aims most relevantly educated nation and well-informed and independent citizens. In this context, various key measures are going to be introduced regarding the rules of how data is used, significant testbeds, AI 
accelerator style operations, ethical self-regulation and online courses for those in working life (Ministry of Economic Affairs and Employment, 2019: 12-124).

\section{Denmark: Digital Growth Strategy}

Denmark published the Digital Growth Strategy in January, 2018. With the intention of creating more prosperity for Danish citizens, Denmark allocated 1 billion Danish Krone (DKK) from 2018 to 2025 for its AI, big data and internet of things projects. Then, 75 million DKK will be allocated for AI activities per year. The strategy aims to make Danish companies adopt digital skills easier and become frontrunner in digital competition by developing its ecosystem. The strategy covers not only data usage, data analysis, e-commerce and digital designs but also cyber-security and data breaches concerns. The government plans to establish a cooperation named "The Technology Pact" between business industry and education institutions and engage next generations with more digital or technical education. Also, it is aimed to test new subjects in primary schools to develop digital and technological competencies of the citizens as well as strengthening computational thinking of the students in primary education (Regeringen, 2019).

The Danish Government published the detailed and extended version of its AI strategy later on. In the extended version 4 key priority areas are defined. These sectors are "healthcare, energy, agriculture and transportation". The government had already taken actions in these sectors and set a strategy entitled "Digital Health Strategy 2018-2022" in healthcare sector, made an "Energy Agreement" in energy and utilities sector, initiated a pilot project named "intelligent irrigation" in agriculture sector and designed an action plan named "The Mobility for the Future" in transportation sector (Ministry of Finance, Ministry of Industry, Business and Financial Affairs, 2019). Being relatively small and easy to govern, Denmark which also possesses efficient technological infrastructure and innovation ecosystem, is an advantageous country compared to the other European countries.

\section{Italy: Artificial Intelligence at the Service of the Citizens}

With the White Paper prepared by AI Task Force of Agency for Digital Italy, Italy has positioned as the third EU country making its mark in AI.

Presented in March 2018, the White Paper underlines digital transformation in the "public administration" and aims to develop services to businesses and citizens with effectively functioning economy. The paper also stresses its anthropocentric approach addressing various universal values such as respecting freedom, ethics, individual and collective rights stating that false use of technologies could damage justice in the society. With this study, Italy aims to find answers to certain questions such as "What types of fundamental skills 
will be needed for future technologies?", "How the education system for the citizens will be evolved?", "How the legal basis will be regulated?" and "How the AI technology will improve the quality of life?". All in all, with more than 500 experts in AI field, Italy plans to take part in AI competition in Europe and the world (Agenzia per L'Italia Digitale, 2018).

\section{France: AI for Humanity}

France showed great enthusiasm and treated AI seriously. The first strategy document in the country was prepared under the leadership of renowned Mathematician and Parliamentarian Cedric Villani. The strategy, named as "Artificial Intelligence for Humanity", was presented by President Emmanuel Macron on March 29 2018.

The AI strategy and vision of France is basically built on three commitments. The first one is to foster French talent and support AI ecosystem coordinated by French National Institute for Computer Science and Applied Mathematics (INRIA) in the country. France has already hosted various AI research centres owned by global tech companies such as Facebook, Google, Samsung, Deepmind, IBM and Fujitsu. It is crystal-clear fact that these companies are going to contribute to the advancement of AI ecosystem in the country. Secondly, France is to establish more than 5 interdisciplinary AI institutes located all across the country housing engineers, researchers and students and set up a network and coordination mechanism among these institutions. Also, researchers working for public mission will be allowed to dedicate half of their working time to private institutions. Lastly, France is planning to increase the number of the students trained in AI double and allocate $€ 1.5$ billion by the end of five-years program, $€ 700$ millions of which to be used in research activities with the intention of developing AI technologies. The document also emphasizes the brain drain from Europe towards the USA and recommends to launch graduate programs to boost the number of students studying on AI (Villani, 2018).

In the strategy documents, France puts forwards a European Data Ecosystem which requires a data pool produced, shared and governed by a community and encourage economic players to share their data pool with the state. Additionally, the strategy document stresses the invisibility of AI companies and networks and adopts the idea of supporting the visibility of these actors in the world. As a matter of fact, France will not reinvent the wheel via trying to establish a European Google. Instead, France has defined 4 key strategic sectors involving "healthcare, environment, transport-mobility and defence-security" and planned to strengthen the AI ecosystem of these sectors. Moreover, the importance of a centre of attraction aggregating big tech companies with freezone facilities, with less bureaucratic and administrative formalities is also 
stressed. Last but not least, the strategy document envisages ecological concerns fostering greener $\mathrm{AI}$ and ethical considerations with social values norms (Villani, 2018).

\section{United Kingdom: AI Sector Deal}

Aiming to develop the AI industry in the country, the United Kingdom ${ }^{2}$ has defined 4 grand challenges and 5 foundations for productivity in its strategy document. The steps which will be taken against the challenges are meeting the needs of aging population, providing clean growth, becoming a world leader in mobility of goods, services and people and being at the forefront in data revolution. Thus, the UK aims to invest in ideas to be the most innovative economy, people to provide better jobs, infrastructure to develop the projects, business environment to grow business and places to enrich communities. To achieve these goals, the UK plans to increase its total R\&D spending to $2,4 \%$ of its GDP by 2027 , raise its tax credit rate of R\&D to $12 \%$ and invest $£ 725$ million GBP in "Industrial Strategy Challenge Fund" to support researchers and businesses in the UK. The country prioritizes its citizens as well. In AI Sector Deal document, the UK declares that it will set up a technical education system and invest additional $£ 406$ million in maths, digital and technical education to improve the citizens' science, technology, engineering and maths (STEM) skills as well as $£ 64$ million for digital and construction training. Additionally, $£ 42$ million will be provided to a pilot program called "Teacher Development Premium" to provide professional development program for teachers (Department for Digital, Culture, Media and Sport, 2019).

The privileged sectors of the UK are life sciences, construction and automotive. The country aims to improve the growth and productivity of SMEs in these sectors and will allocate $£ 1.7$ billion to establish "Transforming Cities Fund" to provide intra-city transportation. Considering $£ 250$ million for autonomous vehicles and $£ 945$ million including $£ 342$ million existing budget and $£ 603$ million support for government, industry and academic contributions, the UK's AI Sector Deal is committed to take part in future technologies' competitions (Department for Digital, Culture, Media and Sport, 2019). The UK has already been in a profitable position in AI competition because of hosting various AI companies such as Google Deepmind, Element AI, Amazon, HPE, Beyond Limits, Ironfly Technologies, Astroscale and Chrysalix in the country.

Companies such as DeepMind, Magic Pony, SwiftKey, Evi and VocallQ had started their operations in the UK before they were purchased by Google, Facebook and Twitter. So, various AI companies such as BenevolentAI and

\footnotetext{
${ }^{2}$ United Kingdom was implicated in the study as the Brexit process was not terminated.
} 
Digital Genius have successfully been developing advanced technologies thanks to the AI market maturity in the country and constructive support of the UK Government. It should be remembered that the UK was one of the first countries to allow the autonomous cars for test driving, that is, autonomous car and auxiliary equipment producers can easily focus on their manufacturing with minimum bureaucracy. It was just an example. Thanks to the investments and incentives by the UK AI Council and Alan Turing Institute, the UK has progressively been an attraction centre for AI investors. Moreover, the UK has the minimum corporation income tax in G7 countries and International Trade Department in the country provides various services for free. The UK's approach to technology and innovation, AI-related policies and companies in the country cannot be underestimated. As the UK Prime Minister Theresa May declares, "AI is keystone of the UK's official industry development strategy" (Slater, 2018). In Tech-Nation Report, May also declares that the UK digital sector has been world-leading and attracted more capital than other EU countries. The UK's developed tech sector contributes to local economies in UK's towns and cities and supports growth, jobs and productivity (Tech Nation, 2018).

In addition to its investments in the innovation ecosystem, digital infrastructure and the private sector, the UK also considers the social dimension of AI and supports the formation of the necessary rules and framework for the regulation of social life. In this context, on behalf of Committee on Standards in Public Life, Lord Evans composed a letter to the Prime Minister informing review decision of the Committee on $\mathrm{AI}$ and use of associated advanced technologies in the public sector in 2019. The letter includes terms of references such as deployment of new technologies in the public sector, good sample, best practises and sufficiency of current frameworks in case of technology-assisted decision-making is upheld. In response to Lord Evans's letter, The Prime Minister express her gratitude for the standards in public life (GOV.UK, 2019). The dynamism in the committee indicates that developments exist not only in the private sector and relevant institutions but also in the legal and social area in the UK.

\section{Sweden: Artificial Intelligence in Swedish Business and Society}

Technology adoption of Swedish public sector, IT infrastructure of the country and digitalisation of Swedish society are in pretty good level compared to other EU countries. More investments in public sector, business and society will both improve the quality of life and contribute to the economic growth and welfare level of the citizens in the country. Considering the technology adoption level of the country, Sweden's strategy document emphasizes mostly on the compatibility of all the stakeholders in the country with digital transformation and AI usage. 
While AI strategy and its relevant projects are being implemented, challenges such as leadership and adaptability, labour dynamics and unemployment, data ownership, data and business monopolies, risk of application of immature AI solutions and security risks will be taken into consideration. Like any other EU countries, Sweden has defined priority areas. These areas are "industrial development, travel and transportation, sustainable and smart cities, healthcare, financial services and security". The implementation methodology of the strategy is based upon a circle composed of 4 factors such as driver, business and operational models, AI competence and data access. These factors will include innovation leadership for the development of AI projects, labour market models for sustainable compatibility, data regulations for assuring privacy, trust and ethics, social solutions for meeting social development needs, critical mass for inclusion of market participants and collaboration among the stakeholders such as research institutions, public bodies and universities. The strategy also analyses the $\mathrm{SWOT}^{3}$ of AI infrastructure. The report tells that AI investments of the rest of the world and possibility of disappearance of simple jobs as threats and lack of state control and unfocused R\&D initiatives in AI as weaknesses. Sweden's strategy doesn't contain policy sets, instead, designed as a guide involving future strategies and compatibility of the stakeholders in the country. Also, the strategy strictly proposes the creation of legal frame of AI in terms of ethics, security and transparency (Vinnova, 2018).

In Sweden, country's innovation agency Vinnova funds various AI projects and it has revealed numerous successful outcomes. Additionally, Nordic Artificial Intelligence Institute located in Stockholm offers strategic counselling, workshops and contributes to the creation of innovation in AI.

\section{Germany: Outline for a German Strategy for Artificial Intelligence}

Initially, Germany prepared an outline with the aim of providing more comprehensive and competitive AI ecosystem in Germany. The strategy outline basically stresses that Germany lags behind in terms of research expenditure and needs to be more open to new AI opportunities and emerging trends such as deep learning. R\&D infrastructure of Germany must be invested more and AI ecosystem must be empowered. In order to strengthen AI ecosystem in the country, not only a budget for R\&D activities should be allocated but also access to data and data sources need to be facilitated easily. The strategy also underlines the ethical dimension of AI strategy. The outline also envisages taking measures to stop or reverse brain-drain and accepts the reality that braindrain can be prevented only if strong ecosystem attracting the expert

${ }^{3}$ SWOT stands for strengths, weaknesses, opportunities, threats and means analysis of these parameters. 
researchers and developers is provided and internalization and visibility of ecosystem is accomplished. Last but not least, German strategy emphasizes the magnitude of effective measurement of outcomes in AI. The number and quality of AI projects, national and international publications, patent registrations, venture capital investments, diversity and growth of companies operating in AI industry should all be considered and elaborated. Only then will Germany be able to get ahead of its rivals in AI (Harhoff, Heumann, Jentzsch, and Lorenz, 2018).

Following the strategy outline announced in July 2018, Germany announced its AI strategy entitled "AI: Made in Germany" and addressed to its old economy which needs a leap in new economic paradigm. The strategy attaches importance to data partnership among companies and production of synthetic data in future AI activities. The strategy aims to promote research for pseudonymization and anonymization procedures and make data sources available for researches emphasizing "responsible use of AI and ethical issues".

As industry giant of the EU, Germany set up Research Centres for Artificial Intelligence called Deutsches Forschungszentrum für Künstliche Intelligenz (DFKI) located in five different cities (Kaiserslautern, Saarbrücken, Bremen, Berlin and Osnabrück). These institutions work collaboratively and contribute to research projects in AI. DFKI hosts qualified researchers, professors from universities, graduate students and visiting researchers from all around the world and conducts research projects in AI (DFKI, 2019).

Germany aims to support SMEs and allocate $€ 3.5$ billion for AI activities by 2025. It is clear that the budget Germany allocated to AI is not comparable when the \$6 billion venture capital for AI spent in the USA in 2017 or \$2 billion spent only for an AI research park in Beijing are considered.

Realizing relatively enhanced AI infrastructure of China, Germany established a non-profit organization in partnership with China. GermanChinese Association of Artificial Intelligence (GCAAI) was established in Germany in 2017 and has been hosting more than 400 experts, researchers, tech leaders and entrepreneurs living or working in China or Germany. The association aims to conduct researches on AI, exchanges practises and support AI industries in both countries (GCAAI, 2019).

\section{Conclusion}

AI has been a fiery competition among the global actors in the last decade. To guide the developments in AI industry, certain European countries have developed numerous AI strategies and programs with different priorities. While Italy concentrates on public administration issues in its AI strategy, Denmark intends to support and boost its companies, start-ups and entrepreneurs. Finland 
emphasizes scientific research and collaborative AI projects with universities while Germany focalizes itself for industrial processes. Actually, most of the EU countries follow suit in their AI strategies more or less and highlight scarcity of experts and projects. Another common point stated in national strategies is related to education, training and digital skills of the citizens. For a sustainable leadership of the EU, education of future generations should be taken into consideration and avant-garde reformative actions and revisions must be realized in curriculum design process.

It seems that AI competition will be based on three trivets; data, financial budget and qualified labour force. Not only the quantity of money allocated for AI but also the AI ecosystem and number of the companies and researchers in AI sector will determine the flag carrier countries in future. It seems that the USA will keep its leading position in the world.

Current data by WIPO indicates that there is only one EU institution out of 20 organizations producing AI-related scientific publications. It means that future's scientific researches are mainly conducted by the USA, China and Japan, and the EU with its 28 members are only represented by CRNS. In this regard, the EU's scientific infrastructure will not be sufficient to compete with other actors in future unless comprehensive reformative actions are taken.

The widely-known reality is that AI will change the content of jobs in future, for the very reason, basic education service must be equipped with digital skills and lifelong learning must be promoted via the EU's policies in all member and partner countries as AI demands for speciality, know-how and adaptive education policies. To be a defacto global actor, the EU needs more policy integration in AI among member countries. Policymakers in the EU must step into action with more comprehensive investment policy, implement incentives, coordinate the member states' national AI strategies to serve at a single purpose and make data accessibility easier for European AI companies.

Data is raw material of AI industry. Data usage, technological readiness and superiority make the USA and China most powerful actors getting the edge over in AI competition. Not only private sector and financial infrastructures but also data ownership and knowledge management will designate the leaders in $\mathrm{AI}$ in the future. In this regard, the EU attaches importance to personal data protection and ethics and ensures a high standards of personal data protection in AI-related digital services. As the measurements of the EU such as ePrivacy and Data Protection Regulation provide free and secure flow of personal data within the EU, the EU citizens' trust in the online world are strengthened. The EU embraces AI in more human-centric dimension with its ethical and societal concerns and considerations and elaborates AI at the service of humankind within the EU's values and fundamental rights. 
Since the EU doesn't have a single national regulation like China, Japan or the USA, it doesn't have single regulatory framework and norms, and cannot prepare central and comprehensive strategy document similar to the ones set by the USA and China. In this context, the EU's AI-related policies haven't moved beyond the plans and strategies of the European Commission. However, differentiated visions and strategies of the EU member countries and endeavours of national governments contribute to the EU's AI policy in general manner. Sharing good practices and synergies, aligning actions and cooperation among member countries will maximise the AI-related investments across Europe and will help the EU compete globally.

While there are discrepancies in the EU countries in the size, financial and institutional structure in $\mathrm{AI}$, the EU, as a supranational entity, locates itself in an incentive and supportive position for member countries to enhance their capabilities and undertakes regulatory role against societal challenges such as environment, health and security. 


\section{References:}

Agenzia per L'Italia Digitale (2018) "AI White Paper Artificial Intelligence at the service of the citizen", 21 March $2018<$ https://ai-whitepaper.readthedocs.io/en/latest/index.html>, (15 May 2019).

Arsenio, A. (2015) "On the Application of Artificial Intelligence Techniques to Create Network Intelligence" in Y. Laalaoui and N. Bouguila (eds), Artificial Intelligence Applications in Information and Communicaton Technologies (Switzerland: Springer) pp.73.

Balasubramanian, R., Libarikian, A. and McElhaney, D. (eds) (2018) Insurance 2030-The impact of AI on the future of insurance. (McKinsey \& Company).

Barton, D., Woetzel, J., Seong , J. and Tian, Q. (eds) (2017) Artificial Intelligence: Implications for China (Beijing: McKinsey Global Institute).

Bloomberg (2019) “Trump's AI Plan Is a Good Start”, 15 February 2019, $<$ https://www.bloomberg.com/opinion/articles/2019-02-15/artificialintelligence-trump-s-smart-american-ai-initiative>, (16 May 2019).

China Institute for Science and Technology Policy (2018) "China AI Development Report”, China Institute for Science and Technology Policy, Beijing.

CNBC (2018) "China is determined to steal A.I. crown from US and nothing, not even a trade war, will stop it", 4 May 2018, $<$ https://www.cnbc.com/2018/05/04/china-aims-to-steal-us-a-i-crown-andnot-even-trade-war-will-stop-it.html>, (3 March 2019).

CNBC (2019) "Google CEO: A.I. is more important than fire or electricity", 1 February 2018, <https://www.cnbc.com/2018/02/01/google-ceo-sundarpichai-ai-is-more-important-than-fire-electricity.html>, (16 May 2019).

Department for Digital, Culture, Media and Sport (2019) “AI Sector Deal Artificial Intelligence Sector Deal”, Department for Digital, Culture, Media and Sport, London.

DFKI (2019) "Deutsches Forschungszentrum für Künstliche Intelligenz" $<$ https://www.dfki.de/en/web/about-us/>, (19 May 2019).

Digital Single Market (2018) "EU Member States sign up to cooperate on Artificial Intelligence", 10 April 2018, <https://ec.europa.eu/digital-singlemarket/en/news/eu-member-states-sign-cooperate-artificial-intelligence>, (20 April 2019).

Digital Single Market (2019) "High-Level Expert Group on Artificial Intelligence", <https://ec.europa.eu/digital-single-market/en/high-levelexpert-group-artificial-intelligence>, (20 April 2019). 
European Commission (2018a) "Towards a common European data space", European Commission, Brussels.

European Commission (2018b) "Artificial Intelligence for Europe", European Commission, Brussels.

European Commission. (2018c) "Coordinated Plan for Artificial IntelligenceMade in Europe", 7 December 2018, <http://europa.eu/rapid/pressrelease_MEMO-18-6690_en.htm>, (26 February 2019)

European Commission. (2019) "Artificial Intelligence", 7 January 2019, $<$ https://ec.europa.eu/digital-single-market/en/artificial-intelligence\#\%22 $\% 20$ name $=>$, (25 February 2019)

European Commission. (2020) "White Paper on Artificial Intelligence-A European approach to excellence and trust", 19 February 2020.

Fortune (2019) "Eye on A.I.- Why You Should Be Concerned About China's Gains in Artificial Intelligence", 9 April 2019, $<$ http://fortune.com/2019/04/09/eye-on-ai-china-artificial-intelligence/ ?xid=gn_editorspicks>, (20 April 2019).

GCAAI (2019) "Who We Are" German-Chinese Association of Artificial Intelligence: <https://www.gcaai.org> , (20 April 2019).

GOV.UK (2019) "Correspondence with the Prime Minister on Artificial Intelligence", 30 April 2019, <https:/www.gov.uk/government/ publications/correspondence-with-the-prime-minister-on-artificialintelligence $>$, (10 March 2019).

GSMA (2018) “The Mobile Economy 2018”, (GSM Association, London).

Günar, A. (2017) "Past Failure, New Future: An Analysis of the European Union Development Strategies-From Lisbon to Europe 2020", in M. Khosrow-Pour (ed) Handbook of Research on Global Enterprise Operations and Opportunities, (Hersey, IGI Global), pp.244-64.

Harhoff, D., Heumann, S., Jentzsch, N. and Lorenz, P. (2018) Outline for a German Strategy for Artificial Intelligence, (Berlin: Stiftung Neue Verantwortung).

Joint Research Centre (2018) Artificial Intelligence A European Perspective (Luxembourg: European Commission).

Judith, S. (2018) "Birleşik Krallık teknoloji firmaları için bir çekim merkezi haline nas1l geldi?", 15 May 2018, Digital Age, British Consulate General Istanbul, Istanbul, Turkey.

Konar, A. (2000) Artificial Intelligence and Soft Computing (Florida: CRC Press).

McKinsey Global Institute (2017a) “Artificial Intelligence The Next Digital Frontier”, McKinsey\&Company. 
McKinsey Global Institute (2017b) "10 imperatives for Europe in the age of AI and automation", McKinsey Global Institute

MIT (2019) “MIT News" <http://news.mit.edu/news-clip/clip-verge-mitinvesting-1-billion-ai-college>, (15 April 2019).

Ministry of Economic Affairs and Employment (2017) "Finland's Age of Artificial Intelligence" (Helsinki: Ministry of Economic Affairs and Employment).

Ministry of Economic Affairs and Employment (2019) Leading the way into the age of artificial intelligence, (Helsinki: Ministry of Economic Affairs and Employment).

Ministry of Economic Affairs and Employment. (2018) Work in the age of artificial intelligence, (Helsinki: Ministry of Economic Affairs and Employment).

Ministry of Economic Affairs and Employment" (2017) "TYÖ- JA ELINKEINOMINISTERIÖ” 18 May $2017<$ https://tem.fi/en/article//asset_publisher/ministeri-lintila-suomesta-tekoalyn-soveltamisenkarkimaa>, (4 March 2019).

Ministry of Finance, Ministry of Industry, Business and Financial Affairs (2019) National Strategy for Artificial Intelligence, (København: Resendahls).

Munakata, T. (2008) Fundamentals of the New Artificial Intelligence, (London: Springer).

National Science and Technology Council (2016) The National Artificial Intelligence Research and Development Strategic Plan, (Washington: OSTP).

Regeringen (2019) "Strategy for Denmark's Digital Growth", $<$ https://eng.em.dk/media/10554/digital-strategy-fact-sheet.pdf>, (27 March 2019).

Research and Markets (2018) Global Artificial Intelligence Market Report 2018, (Dublin: PRNewswire).

South China Morning Post (2019) "China looks to school kids to win the global AI race", 3 May 2018, <https://www.scmp.com/tech/chinatech/article/2144396/china-looks-school-kids-win-global-ai-race>, (12 April 2019).

Tech Nation (2018) "Connection and collaboration: powering UK tech and driving the economy" Tech Nation, London.

Tecuci, G. (2012) “Artificial Intelligence" Wiley Interdisciplinary Reviews: Computational Statistics, 4(2): 168-80.

Villani, C. (2018) For A Meaningful Artificial Intelligence (Paris). 
Vinnova (2018) Artificial Intelligence in Swedish Business and Society, (Vinnova - Sveriges innovationsmyndighet).

White House (2019) "Executive Order on Maintaining American Leadership in Artificial Intelligence", 11 February 2019, $<$ https://www.whitehouse.gov/presidential-actions/executive-ordermaintaining-american-leadership-artificial-intelligence/>, (15 April 2019).

World Intellectual Property Organization (2019) WIPO Technology Trends 2019 (Geneva: WIPO). 